\title{
Keruntuhan Dinding Penahan Tanah dan Mitigasi Lereng di Dusun Bantas, Desa Songan B, Kecamatan Kintamani
}

\author{
Retaining Wall and Slope Failure Mitigation in Bantas Hamlet, \\ Songan B Village, Kintamani Sub-Districts
}

\author{
I Nengah Sinarta ${ }^{1, a)}$ \& I Wayan Ariyana Basoka ${ }^{1)}$ \\ 1) Jurusan Teknik Sipil, Universitas Warmadewa, Denpasar.
}

Koresponden : a)inengahsinarta@gmail.com

\begin{abstract}
ABSTRAK
Dinding Penahan Tanah (DPT) yang berlokasi di Dusun Bantas, Desa Songan B, Kecamatan Kintamani, Kabupaten Bangli secara geografis terletak pada koordinat: $08^{\circ}$ 13 ' 03,5" Lintang Selatan dan $115^{\circ} 24^{\prime}$ 57,9" Bujur Timur, mengalami keruntuhan pada 10 Februari 2017. Keruntuhan terjadi sehari setelah hujan ekstrim yang terjadi selama 4 hari mengguyur daerah sekitar Kecamatan Kintamani pada bulan Februari. Tingginya kerusakan yang terjadi perlu dilakukan analisa teknis untuk mengetahui penyebab terjadinya keruntuhan melalui observasi dan pengamatan di lapangan dan data-data terkait laporan dari dinas terkait. Tujuan dari analisa ini adalah agar DPT yang akan dibangun kembali menjadi lebih kokoh untuk menahan beban dan menghindari terulangnya kejadian serupa pada bangunan yang baru.

Dari observasi dan fakta lapangan dan analisa numeris pada lereng longsor, keruntuhan DPT disebabkan oleh karena dimensi DPT yang terlalu ramping sehingga tidak mampu menahan tekanan tanah aktif saat jenuh air. Drainase DPT tidak berfungsi dengan baik sehingga tanah gampang jenuh saat hujan. Keruntuhan juga disebabkan oleh tergerusnya pondasi DPT akibat masuknya air pada retakan horisontal pada bahu jalan. Pondasi DPT tidak berada pada lapisan tanah yang stabil.

Penanggulangan risiko bencana diawali dengan penilaian dan pemetaan risiko bencana. Pembelajaran terhadap masyarakat didaerah rawan bencana longsor dilakukan secara intensif agar mampu menilai secara visual ancaman terjadi. Upaya mitigasi lebih efektif lainnya dengan investasi pengurangan risiko bencana berupa penerapan system peringatan dini dengan teknologi tepat guna.
\end{abstract}

Kata Kunci : manajemen infrastruktur, dinding penahan tanah, mitigasi bencana, GeoSlope.

\section{PENDAHULUAN}

Ancaman bencana alam telah terjadi perubahan paradigma dalam penanggulangan bencana mulai dikedepankan, yaitu: (1) dari sebelumnnya reponsif menjadi berorientasi pencegahan, (2) dari sebelumnya pendekatan sektoral menjadi multisektoral, (3) dari sebelumnya merupakan inisiatif pemerintah menjadi tanggung jawab bersama, (4) dari sebelumnnya sentralisasi menjadi lebih terdesentralisasi, dan (5) dari sebelumnnya terfokus pada tanggap darurat menjadi lebih berorientasi pada pengurangan resiko bencana. (Fathani, 2018). Modifikasi skala bobot pada masing-masing parameter dalam penyusunan peta ancaman sangat dipengaruhi juga oleh pengalaman individu yang melakukan pembobotan, sehingga dapat dinyatakan bahawa metode ini bersifat subjektif (Sinarta dkk. 2016a). 
Ancaman gerakan tanah di kawasan kaldera Gunung Batur dalam (Sinarta dkk, 2016b), dengan analisis AHP menunjukkan bahwa wilayah tersebut berada pada tinggian 500 - 2000 mdpl, dengan persentase ancaman tinggi sebesar $11 \%$ dan sangat tinggi $9 \%$. Berdasarkan Peta kontur dan analisa kemiringan lereng untuk Kabupaten Bangli memiliki kemiringan tanah di atas $40 \%$ yang sebarannya terutama terdapat pada di seluruh dinding Kaldera Gunung Batur, baik kaldera luar maupun kaldera dalam serta pada beberapa spot kawasan tersebar di wilayah Kecamatan Kintamani lainnya serta di pinggir sungai. Kawasan-kawasan tersebut merupakan kawasan yang termasuk dalam zona kerentanan gerakan tanah tinggi (Sinarta dkk 2017).

Tingginya bencana tanah longsor di Kecamatan Kintamani telah menyebabkan kerugian besar baik korban jiwa manusia dan harta benda seperti peristiwa bencana tanah longsor yang terjadi pada 10 Februari 2017 dibeberapa tempat secara bersamaan yaitu; di Dusun Bantas (Desa Songan B) Gambar 1 (c), Desa Sukawana, Desa Awan, Dusun Yeh Mampeh, Desa Subaya. Peristiwa bersama tersebut terjadi akibat curah hujan ekstrim selama 3 hari pada tanggal 9 - 11 Februari 2017 dengan intensitas hujan 218,7-288 mm/hari (Tim Analisa Stasiun Klimatologi Jembrana, 2017).

Keruntuhan sebuah Dinding Penahan tanah (DPT) yang berlokasi di Dusun Bantas, Desa Songan B, Kecamatan Kintamani, Kabupaten Bangli secara geografis terletak pada koordinat: $08^{\circ} 13$ ' 03,5" Lintang Selatan dan $115^{\circ} 24^{\prime}$ 57,9" Bujur Timur, mengalami keruntuhan pada 10 Februari 2017. Keruntuhan terjadi sehari setelah hujan ekstrim yang terjadi selama 4 hari mengguyur daerah sekitar Kecamatan Kintamani pada bulan Februari. Peristiwa tersebut menimbulkan 5 rumah tertimbun (hancur), 2 mobil, 4 sepeda motor dan 5 sepeda rusak berat, $24 \mathrm{kk}$ diungsikan, serta 7 orang meninggal, 3 orang luka berat, 4 orang luka ringan.

DPT merupakan infrastruktur vital bagi kestabilan kawasan dengan kemiringan tinggi. Oleh karena itu dinding penahan tanah harus dikelola dengan baik sesuai prinsip dasar Manajemen Aset Infrastruktur. Salah satu hal yang harus diperhatikan dalam Manajemen Aset Infrastruktur adalah faktor Resiko (Suprayitno \& Soemitro 2018). Salah satu Resiko penting bagi DPT adalah keruntuhan DPT. Hal ini harus bisa dikelola dengan baik.

Berdasarkan hal tersebut perlu dilakukan analisis teknis terhadap penyebab runtuhnya DPT sehingga terjadinya longsor berdasarkan pengaruh intensitas curah hujan dan drainase di wilayah tersebut. Hasil dari penelitian ini dapat memberikan Informasi sebagai usaha mitigasi bencana alam tanah longsor dalam penanggulangan dan pencegahan bencana untuk dijadikan pedoman pemerintah dan masyarakat dalam penataan wilayahnya yang permukimannya berada di sekitar DPT.

Makalah ini menyampaikan hasil analisis teknis penyebab terjadinya kerunuthan DPT dan pemikiran mengenai upaya mitigasinya.

\section{TINJAUAN LITERATUR}

Konstruksi penahan agar tanah tidak longsor umumnya menggunakan dinding dengan bahan pasangan batu kali atau beton. Konstruksi dinding penahan ini digunakan untuk tebing yang curam atau mendekati tegak.

Penggunaan dinding penahan tanah juga digunakan untuk daerah khusus seperti suatu jalan dibangun berbatasan dengan sungai, danau atau tanah rawa. Bahan yang digunakan di belakang dinding penahan tanah disebut tanah urugan (backfill), penggunaan tanah urugan sebaiknya menngunakan tanah berbutir kasar sehingga lolos air seperti; pasir, kerikil atau batu pecah. Penggunaan tanah lempung sangat tidak disarankan untuk digunakan sebagai tanah urugan. 
Penggunaan dinding penahan tanah dalam perencanaan disamping mempertimbangkan aspek ekonomi sangat penting adalah pertimbangan teknis dengan mempertimbngakan sifatsifat tanah asli, kondisi tanah urugan, kondisi lingkungan setempat dan kondisi lapangan.

Secara umum, dalam Hardiyatmo (2012) dinding penahan dibagi dalam empat kategori, yaitu dinding gravitas (gravity walls), dinding kantilever (cantilever walls), dinding diangker (tied-back walls), serta dinding tanah bertulang (reinforced soil walls).

1. Dinding gravitasi, yaitu dinding dengan fondasi yang berfungsi menahan gaya geser dan gaya guling, seperti dinding pasangan batu kali, dinding dengan perkuatan bronjong, dan dinding beton tak bertulang, dan lain-lain.

2. Dinding kantilever, yaitu dinding dengan dukungan kantilever vertikal atau miring dengan tinggi lereng maksimum 8 meter, seperti dinding kantilever beton bertulang (cantilever concrete retaining walls), turap (sheetpile walls), dan lain-lain. Dinding diangker, yaitu dinding dengan permukaan vertikal atau miring yang ditahan oleh angker, seperti tied-back soldied pile walls, ground-anchored systems, dan tied-back slurry trench walls.

3. Dinding tanah bertulang, adalah tanah yang diperkuat dengan pelat metal, pelat plastik, grid, soil nails atau fabrikasi perkuatan yang dapat memberikan kestabilan internal (Cornforth, 2005).

4. Dinding tanah bertulang, adalah tanah yang diperkuat dengan pelat metal, pelat plastik, grid, soil nails atau fabrikasi perkuatan yang dapat memberikan kestabilan internal (Cornforth, 2005).

Dinding penahan tanah dibangun dengan tujuan untuk memberikan dukungan lateral pada tanah atau batuan. Dalam beberapa kasus dinding penahan tanah juga mendukung beban vertikal seperti dinding ruang bawah tanah dan abutment jembatan (Day, 2002).

Acuan dapat dalam pemilihan dinding penahan tanah sebagai berikut; a) dinding dari pasangan batu dan dinding penahan gravitasi dapat digunakan untuk ketinggian $2-5 \mathrm{~m}$; b) dinding penahan dengan balok kantilever digunakan untuk ketinggian $3-8 \mathrm{~m}$; c) dinding penahan dengan plat penopang digunakan untuk ketinggian $8-15 \mathrm{~m}$.

Langkah awal penentuan dimensi penahan tanah dari konstruksi pasangan batu atau bata seperti dalam Gambar 1.

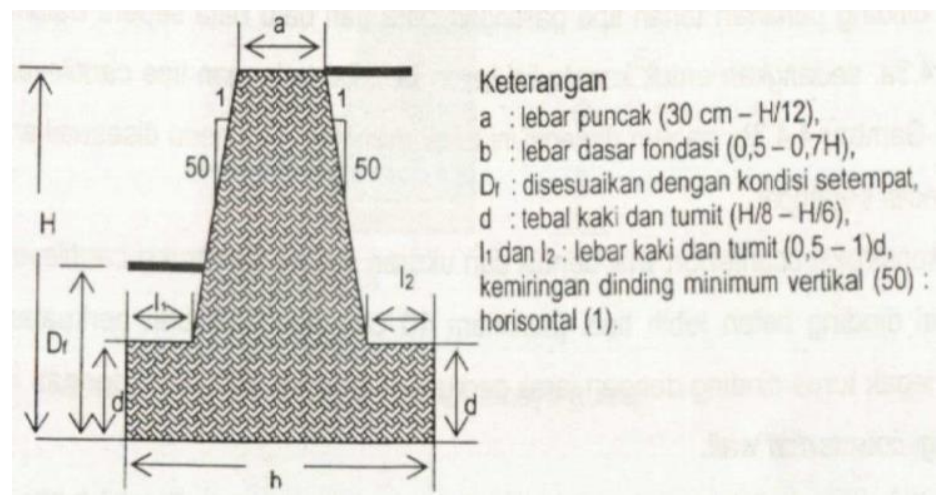

Gambar 1. Perkiraan Dimensi Dinding Gravitasi

(Suryolelono, 2004)

\section{METODOLOGI PENELITIAN}

Kajian terhadap keruntuhan terhadap dinding penahan tanah dalam tulisan ini berdasarkan atas studi investigasi lapangan dan studi literatur sebagai berikut: 1) Pengambilan sample tanah (disturbed sample) pada lokasi longsor 2) pemeriksaan sifat fisik dan mekanik; 3) Analisis stabilitas lereng menerus (infinite slope) dengan geostudio dan 4) Upaya mitigasi 
bencana. Sifat-sifat fisik seprti berat volume, berat jenis, kadar air, dan distribusi butiran tanah. Sedangkan sifat mekanik meliputi kohesi dan sudut geser dalam dari masa tanah.

Analisis stabilitas lereng dengan Metode Limit Equilibrium dengan bantuan program Slope/W dan Seep/W dalam Geostudio 2012 (Acharya, dkk, 2016), berdasarkan data lapangan dan dibandingkan dengan kondisi di lapangan dimana sebuah lereng mengalami keruntuhan yaitu nilai faktor keamanan mendekati 1. Penelitian yang dilakukan hanya meninjau nilai faktor keamanan, akibat dari infiltrasi air hujan (Sinarta, 2018).

Data curah hujan berdasarkan analisis curah hujan ekstrim di Kintamani (Bangli) tanggal 9 Februari 2017 oleh BMKG Jembrana-Bali. Intensitas hujan yang terjadi saat itu rata-rata terbesar sebesar $125 \mathrm{~mm} /$ hari dengan durasi 5 jam. Analisa infiltrasi dengan memodelkan rembesan kedalam tanah akibat pengaruh hujan digunakan metode numerik, program SEEP/W dari Geostudio (GEO-SLOPE International, 2010).

\section{HASIL DAN DISKUSI}

\section{Analisis Teknis}

Berdasarkan laporan singkat tim tanggap bencana tanah longsor pada 15 Maret 2017 seperti terlihat pada Gambar 2, menunjukkan posisi dinding penahan tanah pada lereng perbukitan terjal dengan kemiringan lereng lebih dari 600 yang berada di pinggir jalan dan perumahan terletak 58 meter dari DPT.

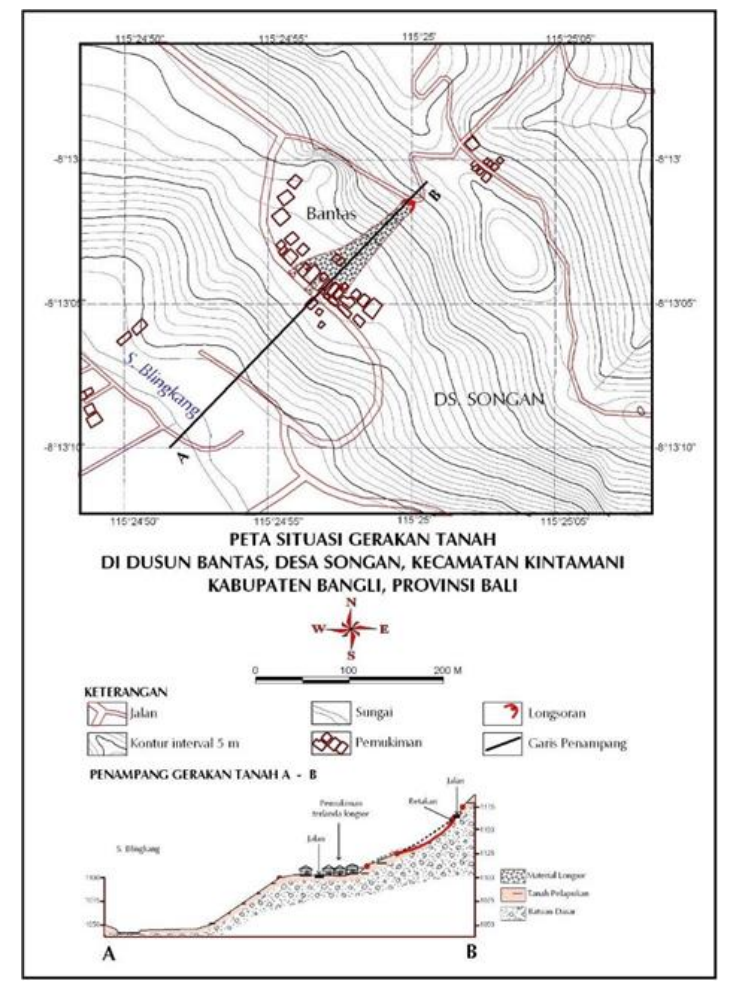

Gambar 2. Peta Situasi Gerakan Tanah di Banjar Bantas (Tim tanggap darurat gerakan tanah, 2017)

Analisis infiltrasi dilokasi longsor menggunakan program SEEP/W, terhadap intensitas curah hujan ekstrim pada selama 3 hari pada tanggal 9 - 11 Februari 2017 dengan intensitas hujan 218,7-288 $\mathrm{mm} /$ hari dengan tinggi curah hujan rata-rata $125 \mathrm{~mm} /$ jam dengan durasi 5 jam, menunjukkan perubahan tekanan air pori pada setiap jam hujan yang terjadi seperti Gambar 3. grafik menunjukkan perubahan tekanan air. 


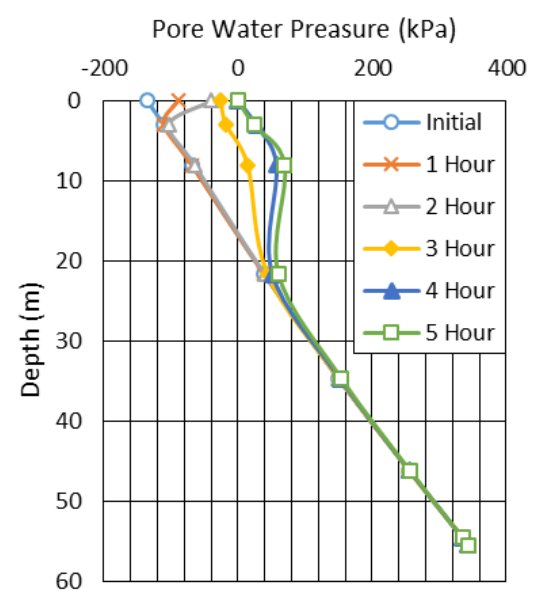

Gambar 3. Grafik Perubahan Tekanan Air Pori (Sinarta, 2018)

Tekanan air pori negatif masih terjadi pada hujan 1 jam, infiltrasi belum mencapai kedalaman kritis pada tanah dibelakang DPT, atau kondisi kondisi jenuh sebagian. Hujan 2 jam sampai 5 jam tekanan air pori menuju positif tanah menjadi jenuh atau kritis.

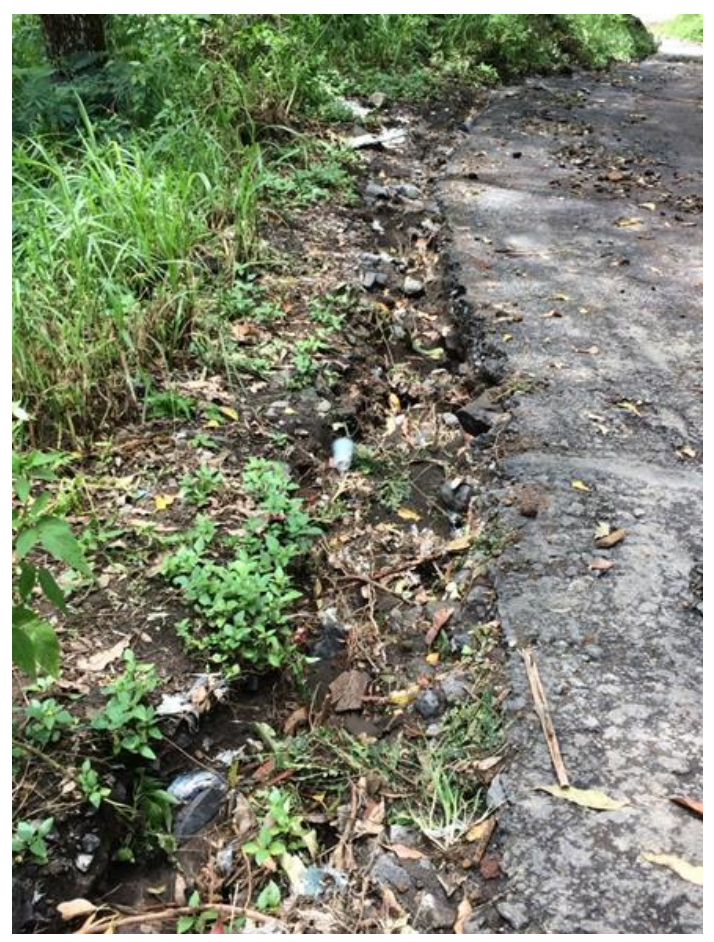

Gambar 4. Retak Horizontal pada Jalan

Tahapan awal Gambar 4 menunjukkan akibat bahu jalan tanpa drainase, limpasan permukaan hujan menyebabkan pengikisan yang menyebabkan retakan horizontal di sepanjang bahu jalan dengan DPT. Kondisi tanah sudah mulai jenuh dan aliran permukaan sepanjang retakan horizontal sepanjang jalan menyebabkan air hujan lebih mudah dan cepat masuk sekaligus menjadi tekanan tambahan terhadap DPT.

Analisis numeris pada penampang lereng dengan sifat fisis dan mekanis tanah dengan program SLOPE/W untuk analisa keruntuhan lereng. Hasil analisis seperti Gambar 5. Grafik hubungan antara angka keamanan dengan lama hujan menunjukkan dengan intensitas curah hujan harian $125 \mathrm{~mm} /$ hari tertinggi dalam durasi hujan selama 5 jam, terjadi penurunan angka 
aman $<1$ pada jam ke 2. Kondisi ini akibat volume hujan konstan dan tinggi menyebabkan rembesan tinggi ke tanah akibat retakan horizontal sehingga air dengan cepat mengisi kekosongan tanah sehingg menyebabkan tekanan air pori meningkat.

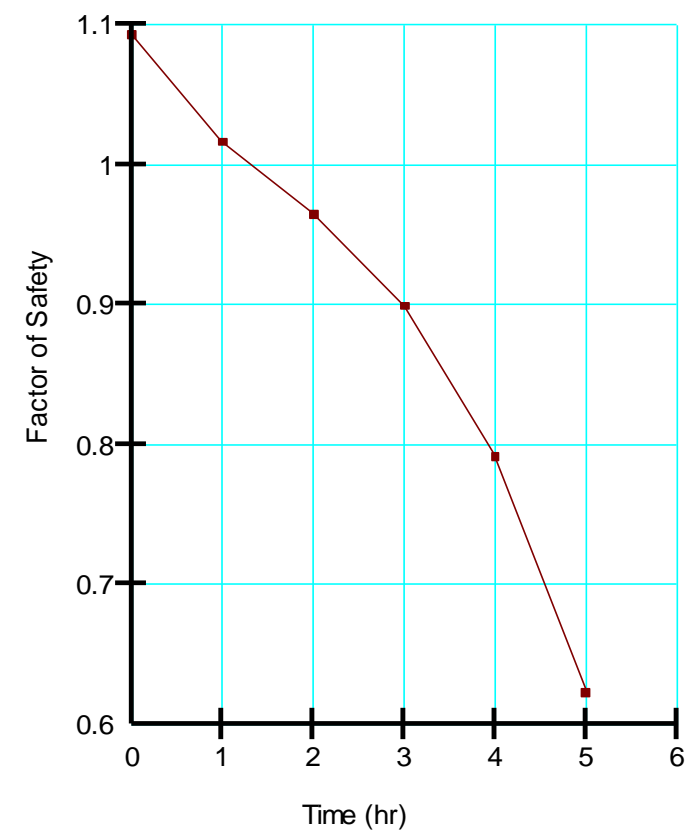

Gambar 5. Hubungan antara Angka Keamanan dan Waktu Hujan

Analisis lingkungan berdasarkan fakta lapangan seperti Gambar 6, menunjukkan bahwa DPT masih kuat sebelum tanah mengalami jenuh air karena hujan yang lebat, terjadi retakan horizontal akibat limpasan permukaan akibat hujan-hujan sebelumnya, deformasi tanah dibelakang DPT akibat retakan tanah dan pergeseran DPT akibat tekanan tanah aktif.

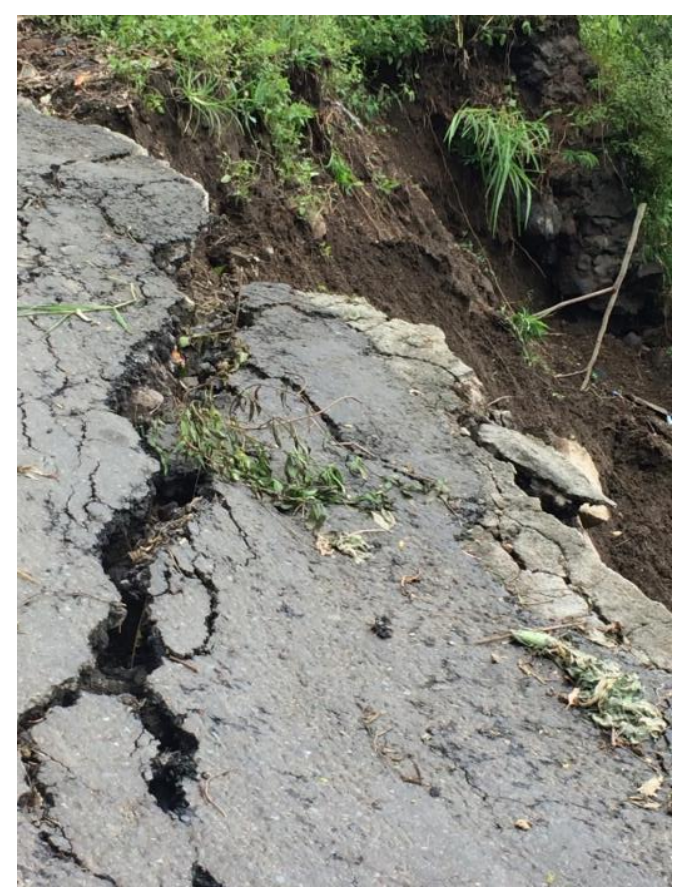

Gambar 6. Runtuhnya Dinding Penahan Tanah 


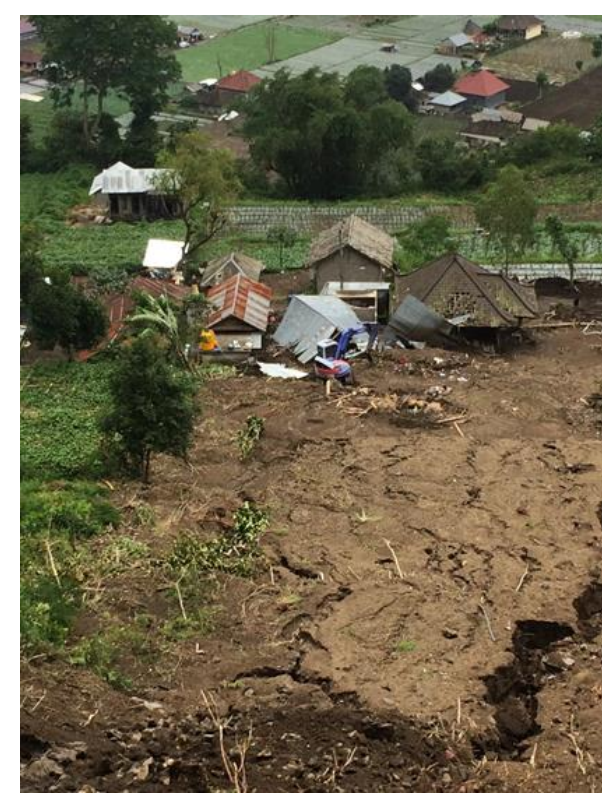

Gambar 7. Tanah Jenuh Air Meluncur

Analisis didasarkan pola dan kejadian keruntuhan DPT di Banjar Bantas, Desa Songan B, Kintamani seperti pada Gambar 7, terjadi pada waktu atau musim hujan, dimana DPT mengalami keruntuhan akibat kondisi yang bersamaan atau kombinasi dari tiga hal yaitu; 1) DPT tidak mampu memikul beban horisontal tanah saat jenuh, 2) tanah dibelakang DPT menjadi gampang jenuh karena drainase DPT tidak berfungsi, 3) pondasi DPT juga mengalami gerusan pada sisi bahu jalan akibat menyusupnya air pada rekatan horizontal.

\section{Langkah Mitigasi}

Akibat intensitas hujan yang tinggi dalam waktu yang panjang pada musim hujan mengakibatkan menurunnya kekuatan geser tanah dan terjadi perubahan karakteristik tanah khususnya pada sifat mekanik yang berhubungan dengan kekuatan geser tanah. Intesitas infiltrasi tanah yang tinggi akibat system drainase yang tidak berfungsi pada lereng yang didominasi tanah berbutir kasar, seperti pasir halus, mempercepat proses penjenuhan sehingga meningkatkan masa tanah.

Sangat diperlukan langkah pengurangan risiko bencana atau mitigasi tanah longsor dengan mengendalikan laju infiltrasi dan meningkatkan kemampuan tanah menahan air sangat dibutuhkan, sehingga DPT tidak mengalami beban berlebih. Usaha mitigasi untuk permukiman yang berdekatan dengan DPT diperlukan sosialisasi termasuk dalam didaerah rawan longsor keruntuhan akibat konstruksi DPT, berupa perubahan visual tanah seperti; penurunan permukaan tanah di belakang DPT, retakan pada DPT dan system drainase permukaan di sekitar DPT agar berfungsi normal, dan Tidak beraktivitas di sekitar DPT pada saat hujan lebat dan berlangsung lama.

Pengendalian lingkungan sangat penting untuk daerah lereng atau perbukitan akibat alih fungsi lahan terjadi secara terus menerus adalah kendala yang secara nyata dihadapi dalam mengendalikan potensi bencana himbauan ini tidak akan mudah untuk dilaksanakan, namun kesiapan dari masyarakat dan pemerintah daerah untuk memberikan edukasi serta wewenang dalam pengendalian tidak terjadi sehingga lahan hunian dan lahan usaha berada pada daerah rawan bencana longsor. 


\section{KESIMPULAN}

Intensitas hujan sebesar $125 \mathrm{~mm} /$ hari dalam durasi lima jam berpengaruh terhadap besarnya infiltrasi yang menyebabkan keruntuhan lereng. Semakin tinggi infiltrasi yang terjadi akibat drainase permukaan yang buruk menyebabkan perubahan tekanan air pori akan semakin besar dan durasi makin panjang menyebabkan genangan atau limpasan permukaan menyebabkan retakan antara DPT dengan bahu jalan.

Berdasarkan analisis numerik dan analisis terhadap lingkungan atau fakta telah terjadi bencana tanah longsor di Banjar Bantas, Desa Songan B, Kintamani disebabkan oleh; 1) DPT tidak mampu memikul beban horisontal tanah dalam kondisi jenuh akibat infiltrasi dari retakan horizontal pada bahu jalan, 2) Pelemahan dasar pondasi oleh air akibat dasar fondasi tidak mencapai tanah keras atau stabil, 3) DPT bertipe grafitasi tidak cukup lebar sehingga berat sendirinya tidak mampu memikul beban horisontal tanah jenuh dan air sehingga terjadi guling.

Penanggulangan risiko bencana diawali dengan penilaian dan pemetaan risiko bencana untuk menentukan daerah berisiko tinggi dan prioritas penanganan. Pembelajaran terhadap masyarakat dalam didaerah rawan bencana longsor perlu dilakuakn secara intensif sehingga masyarakat dapat atau mampu menilai secara visual ancaman ynag mungkin terjadi sehingga segera dapat melakukan evakuasi. Upaya mitigasi yang lebih efektif yang menjadi bagian penting dari investasi pengurangan risiko bencana adalah penerapan system peringatan dini menggunakan teknologi tepat guna.

\section{DAFTAR PUSTAKA}

Acharya, K. P., Bhandary, N. P., Dahal, R. K., \& Yatabe, R. (2016). Seepage and slope stability modelling of rainfall-induced slope failures in topographic hollows. Geomatics, Natural Hazards and Risk, 7(2), 721-746.

Cornforth, D. H. (2005). Landslides in Practice: Investigation, Analysis and Remedial/Preventative Options in Soils. Second Edition. John Wiley \& Sons, Inc. Canada.

Day, R. (2002). Geotechnical Earthquake Engineering Handbook. McGraw-Hill Company. Callgary, Alberta, Canada T2P 2Y5

Fathani, T. F. (2018). Penegakan Kedaulatan Teknologi Nasional Dalam Penanggulangan Bencana Gerakan Tanah. Pidato Pengukuhan Guru Besar. Departemen Teknik Sipil dan Lingkungan, Universitas Gadjah Mada, Yogyakarta.

GEO-SLOPE International (2010). Seepage Modeling with SEEP / W 2007. Geostudio Helpfile, (February), 307.

Hardiyatmo, H. C. (2012). Tanah Longsor dan Erosi: Kejadian dan Penanganan. Gadjah Mada University Press. Yogyakarta.

Sinarta, I. N. (2018). Tingkat Ancaman Gerakan Tanah Pada Batuan Vulkanik Di Bali Berdasarkan Pendekatan Geoteknik Komprehensif. Disertasi. Universitas Gadjah Mada. Yogyakarta.

Sinarta, I.N., Rifa'i, A., Fathani, T.F. and Wilopo, W., (2017). "Landslide Hazards Due To Rainfall Intensity in the Caldera of Mount Landslide Hazards Due To Rainfall Intensity In." The 1st Warmadewa University International Conference on Architecture and Civil Engineering SUSTAINABILITY, DESIGN AND CULTURE 20th October 2017, Faculty of Engineering, Warmadewa University, Bali LANDSLIDE, vol. 1, 2017, pp. 160-67

Sinarta, I. N., Rifa'i, A., Fathani, T. F., \& Wilopo, W., (2016a). Pemetaan Ancaman Gerakan Tanah Berdasarkan Indeks Stabilitas pada ekstensi SINMAP di Kabupaten Bangli, Bali. Proseding Seminar Nasional Geoteknik 2016, HATTI, Yogyakarta, ISBN: 978-60271762-4-9. 
Sinarta, I.N., Rifa'i, A., Fathani, T.F. and Wilopo, W., (2016b). Indeks Ancaman Gerakan Tanah Dengan Metode Analythical Hierarchy Process (AHP) Untuk Penataan Infrastruktur Kepariwisataan Di Kawasan Geopark Gunung Batur, Kabupaten Bangli, Bali. Seminar Nasional KonsepSi\#2 (Konsep dan Implementasi 2), 1, pp.110-120.

Suprayitno, H. \& Soemitro, R.A.A. (2018). "Preliminary Reflexion on Basic Principle of Infrastructure Asset Management". Jurnal Manajemen Aset Infrastruktur \& Fasilitas, Vol. 2, No. 1, Maret 2018, Hal. : 1-9.

Suryolelono, Kabul Basah. (2004). Perancangan Fondasi. Edisi 1. Gadjah Mada University Press. Yogyakarta.

Tim Analisa Stasiun Klimatologi Jembrana. (2017). Analisis Banjir Bandang Dan Tanah Longsor Di Sekitar Bedugul (Buleleng) Dan Kintamani (Bangli) Tanggal 9 Februari 2017, BMKG, Stasiun Klimatologi Kelas II Jembrana - Bali.

Tim Tanggap Darurat Gerakan Tanah. (2017). Laporan Singkat Bencana Gerakan Tanah Kecamatan Kintamani, Kabupaten Bangli, Provinsi Bali, Badan Penanggulangan Bencana Daerah (BPBD) Bali. 
(e)ISSN 2615-1847 (p)ISSN 2615-1839

Jurnal Manajemen Aset Infrastruktur \& Fasilitas - Vol. 3, Edisi Khusus 1, Maret 2019 